\title{
The improved evaluation of the duration of the fouled membrane modules regeneration
}

\author{
Serhii Huliienko, Ihor Tereshenko \\ Department of Machines and Apparatus of Chemical and Oil Refinery Productions, National Technical University \\ of Ukraine "Igor Sikorsky Kyiv Polytechnic Institute", UKRAINE, Kyiv, Prosp. Peremohy, 37, 03056, E-mail: \\ sergii.guliienko@gmail.com
}

\begin{abstract}
The calculations of the duration of the membrane modules regeneration using the corrected dimensionless equation were carried out. It was defined that proposed equation allows avoiding the overestimation of regeneration time. The results show that assumption about the negligible influence of the concentration change in the cleaning solution is reliable.
\end{abstract}

Keywords: fouling, membrane, regeneration, dimensionless equation, calculation, cleaning solution, mass transfer coefficient.

\section{Introduction}

Membrane fouling is one of the main problems during the exploitation of membrane equipment, which determines the necessity of periodic membrane regeneration [1]. In previous work, the method of the spiral wound membrane modules regeneration with using of vacuuming was developed. The mathematical model of this process, which allows calculating the regeneration process duration, also was proposed [2]. However, in that work the dimensionless equation was used, which was obtained with several assumptions that lead to the overestimation of the mass transfer coefficient. This equation was corrected in work [3]. The current work aims to carry out the improved evaluation of the regeneration time taking into account the corrected dimensionless equation. Also, in work [2] the influence of the changes in cleaning solution concentration wasn 't taken into account, therefore, the improved evaluation has also aimed to verify the reliability of that assumption.

\section{Materials and methods}

The process of mass removal from the membrane surface is described by the equation [2]:

$$
\frac{d M}{d \tau}=K\left(C^{p}-C_{0}-\frac{M_{\Pi}}{V}\left(1-\frac{M_{\Pi}-M}{M_{\Pi}}\right)\right) F
$$

The starting conditions are: $M=0$ for $\tau=0$.

The determination of mass transfer coefficient $K$, unlike work [2], in the current research the following dimensionless equation was used [3]:

$$
\mathrm{Sh}=0.00045 \operatorname{Re}^{0.8} \mathrm{Sc}^{0.33}\left(d_{e} / l\right)
$$

The solving was carried out by the Runge-Kutta, the calculations were done using the program written in the programming language Python in two variants (with and without taking into account the concentration change in cleaning solution).

\section{Results and discussion}

The calculations were carried out for the case of the fouling which consists of $\mathrm{FeCl} 3$ (this material used as model foulant in experimental researches) with an initial mass of $0.002 \mathrm{~kg}$, and an operating temperature of $25^{\circ} \mathrm{C}$. The mass flow rate of the cleaning solution in a range of 0.001 $0.025 \mathrm{~kg} / \mathrm{s}$. which correspond to the real working condition of the regeneration setup. The results of the calculation are represented in table 1. 
The results of calculations

\begin{tabular}{|c|c|c|c|c|}
\hline $\begin{array}{c}\text { The mass } \\
\text { flow rate of } \\
\text { the cleaning } \\
\text { solution, } \\
G, \mathrm{~kg} / \mathrm{s}\end{array}$ & $\begin{array}{c}\text { With taking into account the } \\
\text { concentration change in cleaning } \\
\text { solution }\end{array}$ & \multicolumn{2}{|c|}{$\begin{array}{c}\text { Without taking into account the } \\
\text { concentration change in cleaning } \\
\text { solution }\end{array}$} \\
\cline { 2 - 5 } & $\begin{array}{c}\text { Reynolds } \\
\text { number, Re }\end{array}$ & $\begin{array}{c}\text { The time of } \\
\text { complete cake layer } \\
\text { removal, } \tau, \mathrm{s}\end{array}$ & $\begin{array}{c}\text { Reynolds } \\
\text { number, Re }\end{array}$ & $\begin{array}{c}\text { The time of complete } \\
\text { cake layer removal, } \\
\tau, \mathrm{s}\end{array}$ \\
\hline 0,0010 & 2,163 & 141000 & 2,163 & 141119 \\
\hline 0,0025 & 5,407 & 67740 & 5,410 & 67801 \\
\hline 0,0050 & 10,814 & 38910 & 10,814 & 38942 \\
\hline 0,0075 & 16,221 & 28130 & 16,221 & 28154 \\
\hline 0,0100 & 21,628 & 22350 & 21,628 & 22366 \\
\hline 0,0125 & 27,035 & 18700 & 27,035 & 18710 \\
\hline 0,0150 & 32,442 & 16160 & 32,442 & 16171 \\
\hline 0,0175 & 37,849 & 14290 & 37,849 & 14295 \\
\hline 0,0200 & 43,256 & 12840 & 43,256 & 11691 \\
\hline 0,0225 & 48,663 & 11690 & 48,663 & 10746 \\
\hline 0,0250 & 54,070 & 10740 & 54,070 & \\
\hline
\end{tabular}

As it can be seen from table 1, the difference in the time of complete cake layer removal for the calculation with and without taking into account the concentration change in the cleaning solution is negligible, therefore, the assumption made in work [2] is reasonable. At the same time, the duration of the regeneration differs significantly. In work [3] it was pointed out that previous mass transfer correlation was obtained with overestimated values of diffusivities. The results of improved calculation show that this led to the overestimation of the regeneration duration in 4-5 times, therefore, for the practical calculation the corrected dimensionless equation should be used.

\section{Conclusion}

The use of the corrected dimensionless equation allows predicting the duration of the membrane modules regeneration with higher accuracy. Moreover, the assumption about the negligible impact of the concentration change in the cleaning solution on the mass transfer coefficient value appears to be reasonable.

\section{References}

[1] Jafari M., D'haese A., Zlopasa J., Cornelissen E.R., Vrouwenvelder J.S., Verbeken K., Verliefde A., van Loosdrecht M.C.M., Picioreanu C. (2020). A comparison between chemical cleaning efficiency in lab-scale and full-scale reverse osmosis membranes: Role of extracellular polymeric substances (EPS). Journal of Membrane Science. Vol. 609, 118189, https://doi.org/10.1016/j.memsci.2020.118189

[2] Korniyenko Y., Guliienko S., Lialka M. (2015). Mathematical simulation of fouled membrane modules regeneration. Ukrainian Food Journal. 2015. Vol. 4. Is. 3, pp. 481-493

[3] Huliienko S. V., Korniienko Y. M., Metlina M. S., Tereshenko I. Y., Kaminskyi V. S. (2020). The correction of the dimensionless equation for the mass transfer coefficient estimation during the membrane modules regeneration. Journal of Engineering Sciences, Vol. 7(2), pp. F24-F29, https://doi.org/10.21272/jes.2020.7(2).f4 